\title{
Early Derangements of Arteriovenous Anastomotic and Capillary Blood Flow in the Canine Hindlimb Induced by Supplemental Pentobarbital Anesthesia
}

\author{
ANDris KazMers, M.D., ${ }^{1}$ Walter M. Whitehouse, JR., M.D., \\ GeRAld B. ZELENOCK, M.D., JACK L. CRONENWETT, M.D., \\ S. Martin Lindenauer, M.D., AND James C. STANLEY, M.D. \\ Division of Peripheral Vascular Surgery, Department of Surgery, University of Michigan \\ Medical School, Ann Arbor, Michigan 48109
}

Submitted for publication December 6, 1982

\begin{abstract}
Vasoactive effects of supplemental pentobarbital anesthesia in the canine hindlimb microcirculation were documented in two groups of animals previously anesthetized with $30 \mathrm{mg} / \mathrm{kg}$ pentobarbital: Group I with a $5 \mathrm{mg} / \mathrm{kg}$ intravenous (iv) bolus of pentobarbital $(n=8)$ and Group II with a $5 \mathrm{mg} / \mathrm{kg} \mathrm{2-min}$ iv infusion of pentobarbital $(n=7)$. In Group 1 , measurements at baseline (BL) and 5, 15, 20, and 30 $\min (\min )$ following pentobarbital administration included cardiac output, mean arterial pressure, total peripheral vascular resistance, common femoral artery flow (CFAQ) and resistance (CFAR), percentage hindlimb arteriovenous anastomotic shunt (AVA\%), absolute shunt flow (AVAQ), and hindlimb nutrient capillary flow (NCQ). In Group II these same measurements were made, but the study was continued until all hindlimb hemodynamic parameters returned to control values. CFAQ, AVA\%, AVAQ, and NCQ were significantly increased, and CFAR was decreased in both groups. CFAQ and NCQ remained significantly elevated at $30 \mathrm{~min}$ in Group I. In Group II CFAR, AVA\%, and AVAQ remained elevated at $30 \mathrm{~min}$, but did return to BL by $40 \mathrm{~min}$, as did all other hindlimb hemodynamic parameters measured. Pentobarbital resulted in both AVA and arteriolar dilation, with an increase in the percentage total flow distributed to AVAs. These alterations of microcirculatory flow should be considered during investigations of the distribution of peripheral blood flow, as well as during metabolic studies assessing arteriovenous substrate differences, if interpretative errors are to be avoided.
\end{abstract}

This investigation was undertaken to define the microcirculatory effects of supplemental pentobarbital, an agent commonly used during hemodynamic studies in experimental animals. Previous studies have suggested that this agent may increase arteriovenous shunting [6, 8]. Although many canine hindlimb shunt studies have employed this anesthetic, to our knowledge, its specific effect on arteriovenous anastomoses has not been defined $[5,9,10$, $12,13]$. In the current investigation, alterations in hindlimb arteriovenous shunting induced by supplemental pentobarbital were quantitated using a radioactive microsphere technique.

\section{MATERIALS AND METHODS}

Fifteen adult mongrel dogs, weighing 21 to $37 \mathrm{~kg}$, were anesthetized with an intravenous

${ }^{1}$ Liebig Fellow in Vascular Surgery. bolus of pentobarbital $(30 \mathrm{mg} / \mathrm{kg})$. Animals were intubated and mechanically ventilated maintaining arterial $\mathrm{pH}, p \mathrm{CO}_{2}$, and $p \mathrm{O}_{2}$ within physiologic ranges. Esophageal temperature remained stable and normal throughout the study. All dogs received lactated Ringer's solution $(10 \mathrm{ml} / \mathrm{kg})$ intravenously during the experiment. A carotid arterial catheter, a transjugular central venous catheter, and a 7-Fr thermodilution SwanGanz catheter were appropriately positioned in each animal. Systemic arterial and central venous pressures were continuously monitored. A nonoccluding squarewave electromagnetic flow probe was placed about the common femoral artery for continuous measurement of total femoral blood flow (CFAQ) using a square wave flowmeter. A NaI scintillation detector calibrated for the detection of technetium- $99 \mathrm{~m}$, was fixed in position over the upper lung fields. Freshly prepared ${ }^{99 \mathrm{~m}} \mathrm{Tc}$ - 
labeled albumin microsopheres with a mean diameter of $20 \mu \mathrm{m}$ (range 15-35 $\mu \mathrm{m}$ ) were used in this experiment (3M Co., Minneapolis). Spheres of this size, when injected in the femoral artery, are trapped in the hindlimb capillary microcirculation unless they pass through arteriovenous anastomoses, whereupon they ultimately lodge in the lung [10]. A 22-gauge Teflon catheter was advanced into the common femoral artery for retrograde intraarterial microsphere administration. Radioactivity in individual syringes containing less than $0.1 \mathrm{ml}$ of the suspension of microspheres $(25,000$ to 37,500 spheres) was measured before and after injection. Syringes were flushed three times with $0.3 \mathrm{cc}$ of autologous blood. Such injections did not alter total common femoral artery flow. The radioactivity actually injected was determined taking into consideration the decay of ${ }^{99 \mathrm{~m}} \mathrm{Tc}$ as well as the residual radioactivity in the syringes after injection. Injection catheter radioactivity was measured, and found to be insignificant. Three minutes following each microsphere injection, the incremental change in radioactivity over the lung was quantified. Femoral venous injections of a known amount of microspheres were used to determine " $100 \%$ shunt," measured as change in counts per minute $(\Delta \mathrm{cpm})$ of radioactivity over the lung field per millicurie radioactivity injected.

Percentage hindlimb shunt was calculated by the standard formula:

\section{$\Delta c p m$ over chest with intraarterial injection/ Percentage shunt (AVA\%) $=\frac{\text { dose of intraarterial injection }}{\Delta \text { cpm over chest with venous injection/ }} \times 100$.}

The volume of blood flow through shunts (AVAQ) was calculated as AVAQ $=\mathrm{CFAQ}$ $X$ AVA\%shunt. The volume of blood flow not passing through arteriovenous anastomoses, and therefore available for capillary exchange as nutrient capillary flow (NCQ), was calculated: $\mathrm{NCQ}=\mathrm{CFAQ}-\mathrm{AVAQ}$.

Two experimental groups were evaluated. Forty minutes after induction of pentobarbital anesthesia hemodynamic parameters appeared stable. Baseline studies were then obtained. Group I subjects $(n=8)$ then received an intravenous bolus of pentobarbital $(5 \mathrm{mg} / \mathrm{kg})$ and hemodynamic studies were continued for the next $30 \mathrm{~min}$. Group II subjects ( $n=7$ ) were studied after a 2-min continuous infusion of the same dose of supplemental pentobarbital, with experimental observations continuing for $40 \mathrm{~min}$. In both Groups I and II the following parameters were measured at baseline (BL) and 5, 15, 20, and $30 \mathrm{~min}$ (and $40 \mathrm{~min}$ in Group II) after pentobarbital injection: cardiac output $(\mathrm{CO})$, central venous pressure (CVP), mean arterial pressure (MAP), systemic vascular resistance $(\mathrm{SVR}=\mathrm{MAP}$ $-\mathrm{CVP} / \mathrm{CO} \times 79.9 \mathrm{dyn}-\mathrm{sec} / \mathrm{cm}^{5}$ ), and com- mon femoral artery resistance $(\mathrm{CFAR}=\mathrm{MAP} /$ CFAQ (liters $/ \mathrm{min}) \times 79.9$, dyn-sec $\left./ \mathrm{cm}^{5}\right)$. Percent shunt, shunt flow (AVAQ), and nonshunt nutrient capillary flow (NCQ) were calculated as previously discussed. Data were analyzed by the Wilcoxon signed rank test and paired Student $t$ test.

\section{RESULTS}

Effects of pentobarbital on cardiac output differed in the two groups (Table 1). In Group I significant abrupt increases in cardiac output occurred, and the elevations persisted for 30 min after bolus administration. The minor increase in mean cardiac output observed in Group II animals never attained statistical significance.

Mean arterial pressure was significantly decreased only at $5 \mathrm{~min}$ in Group I. Although mean arterial pressure decreased in Group II animals, changes from baseline approached but did not attain statistical significance at any time. Systemic vascular resistance was decreased significantly in both groups, indicating 
TABLE 1

Systemic EFFECTS Of Pentobarbital ${ }^{a}$

\begin{tabular}{|c|c|c|c|c|c|c|}
\hline & Baseline & $5 \mathrm{~min}$ & $15 \mathrm{~min}$ & $20 \mathrm{~min}$ & $30 \mathrm{~min}$ & $40 \mathrm{~min}$ \\
\hline \multicolumn{7}{|c|}{ Cardiac output $(1 / \mathrm{min})$} \\
\hline Group I & $3.96 \pm 1.11$ & $5.53 \pm 2.26^{*}$ & $5.32 \pm 1.62^{*}$ & $4.91 \pm 1.09^{*}$ & $5.40 \pm 1.24^{* *}$ & - \\
\hline Group II & $3.96 \pm 0.78$ & $4.19 \pm 0.86$ & $4.08 \pm 0.86$ & $4.15 \pm 0.77$ & $4.38 \pm 1.11$ & $4.70 \pm 0.88$ \\
\hline \multicolumn{7}{|c|}{ Mean arterial pressure $(\mathrm{mm} \mathrm{Hg})$} \\
\hline Group I & $140 \pm 17$ & $136 \pm 19^{*}$ & $137 \pm 18$ & $138 \pm 18$ & $140 \pm 15$ & - \\
\hline Group II & $141 \pm 13$ & $135 \pm 17$ & $132 \pm 17$ & $133 \pm 12.2$ & $133 \pm 14$ & $142 \pm 12$ \\
\hline \multicolumn{7}{|c|}{ Systemic vascular resistance (dyn-sec/ $\mathrm{cm}^{5}$ ) } \\
\hline Group I & $3048 \pm 1139$ & $2144 \pm 729^{* *}$ & $2178 \pm 652^{* *}$ & $2297 \pm 641^{*}$ & $2147 \pm 588^{*}$ & - \\
\hline Group II & $3028 \pm 620$ & $2751 \pm 573$ & $2778 \pm 612$ & $2728 \pm 476^{*}$ & $2632 \pm 553^{* *}$ & $2575 \pm 568^{* *}$ \\
\hline
\end{tabular}

that pentobarbital caused vasodilatation independent of the speed of administration.

Major effects on hindlimb hemodynamics were apparent after supplemental pentobarbital administration (Table 2). Common femoral artery flow in Group I increased significantly throughout the period of observation. In Group II, the peak increase in CFAQ occurred at $20 \mathrm{~min}$, but returned toward control values by $30 \mathrm{~min}$. Decreases in hindlimb vascular resistance were observed in both groups, but had returned to levels indistinguishable from control values by $30 \mathrm{~min}$ in Group I, and by $40 \mathrm{~min}$ in Group II.

Percentage hindlimb shunt more than doubled in each group. In Group I mean percentage shunt increased from $3.2 \%$ at baseline to $8.2 \%$ at $5 \mathrm{~min}$, and in Group II from a baseline of 2.1 to $6.0 \%$ at $20 \mathrm{~min}$. Percentage hindlimb shunt returned to values near control levels by $30 \mathrm{~min}$ in Group I, and by $40 \mathrm{~min}$ in Group II.

Reflecting this redistribution of blood flow to AVA, absolute shunt flow (AVAQ) more than tripled in both groups. Bolus pentobarbital administration resulted in an early increase of mean AVAQ from $3.9 \mathrm{ml} / \mathrm{min}$ baseline to $12.3 \mathrm{ml} / \mathrm{min}$ at $5 \mathrm{~min}$ with a subsequent return toward control levels by $30 \mathrm{~min}$. In Group II peak shunt flow occurred at $20 \mathrm{~min}$, being similar in magnitude to the maximum shunt flow in the Group I animals, $12.9 \mathrm{ml} /$ min. By $40 \mathrm{~min}$ in Group II, AVAQ also had returned close to control values.

Hindlimb nutrient capillary flow (NCQ) in Group I remained significantly elevated compared to baseline values throughout the study period. In Group II, mean NCQ increased from $142 \mathrm{ml} / \mathrm{min}$ at baseline to a maximum of $190 \mathrm{ml} / \mathrm{min}$ at $20 \mathrm{~min}$, returning toward control levels by $40 \mathrm{~min}$. Maximum derangements in the hindlimb microcircuation occurred in Group I at the initial 5-min observation period, and were noted at $20 \mathrm{~min}$ in Group II.

\section{DISCUSSION}

The radioactive microsphere technique for study of canine hindlimb arteriovenous anastomoses was first introduced by Lopez-Majano et al. [10]. Many investigators have subsequently evaluated the effects of pharmacologic and physiologic manipulations on these naturally occurring arteriovenous shunts, but despite this, the functional significance and physiologic control of AVA remain poorly understood.

Several suggestions that pentobarbital may alter arteriovenous shunting exist in the literature. Kaihara and colleagues reported that radioactivity accumulations in the lungs were 
KAZMERS ET AL: AVA FLOW AND PENTOBARBITAL

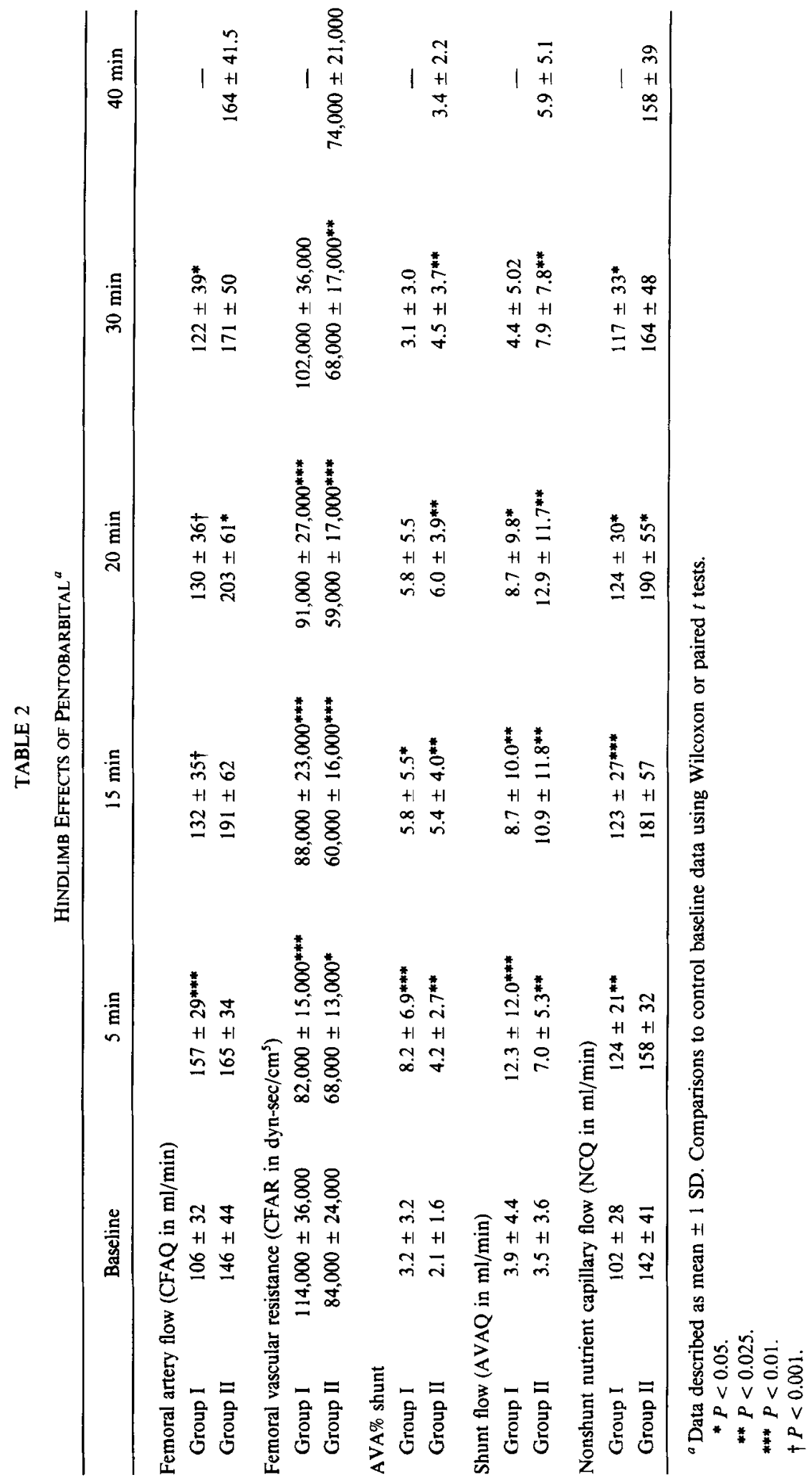


significantly higher with left atrial injection of radioactive microspheres in dogs anesthetized with 25 to $30 \mathrm{mg} / \mathrm{kg}$ of pentobarbital, than occurred with similar microsphere injections in unanesthetized dogs [8]. These investigators speculated that this might result from "diversion of these spheres around systemic vascular beds" [8]. Rhodes and his coauthors reported existence of "a wider variation in percent shunting in pentobarbital anesthetized dogs" [12]. Another investigation on regional distribution of blood flow during pentobarbital administration noted marked increases in lung microsphere entrapment and decreased skeletal muscle blood flow [6]. Although these investigators speculated that systemic arteriovenous shunting resulted from pentobarbital administration, shunting was never quantitated by direct measurement.

Results of our study indicate that pentobarbital acts as an arterial dilator when administered by intravenous bolus or slow infusion in dogs already anesthetized with this drug. Hemodynamic responses to pentobarbital appear similar when administered to animals already anesthetized with this barbiturate or when administered to dogs previously anesthetized with other agents such as choloralose or urethane [11]. Lowering of arterial pressure and systemic vascular resistance following administration of $5 \mathrm{mg} / \mathrm{kg}$ of pentobarbital are comparable with drug induced vasodilation which has been previously reported $[6,11]$. Because the effects of other anesthetic agents on hindlimb arteriovenous shunt are unknown, and because of the pervasive use of pentobarbital anesthesia in research related to arteriovenous anastomotic blood flow, pentobarbital was used to induce anesthesia in this study. This dose of pentobarbital was chosen for study because it is a frequently used anesthetic supplement in canine experiments.

An important microcirculatory derangement induced by supplemental pentobarbital anesthetic is an increase in percent of hindlimb shunt. This phenomenon may be due to relaxation or active dilation of AVAs. Accordingly, increased volume flow through such shunts may theoretically result from either "opening" of the AVA, or by increases in volume flow through AVA following proximal arterial dilation [9]. Both phenemona may have been operative in our experiments. Pentobarbital also increased hindlimb nutrient capillary blood flow, which may result from arterial dilation. Previous "vital" studies have suggested that pentobarbital causes venodilation as assessed by increased venular size, in addition to arterial dilation [7]. The increased venular size, reported in the former study, may reflect increased arteriovenous shunting, greater flow with arteriolar dilation, or primary venodilation. Specific mechanisms by which pentobarbital causes vasodilation are unclear, but may include inhibition of vasoconstriction by endogenous epinephrine, by acting as a "calcium entry blocker," or by inhibition of vasomotion [1, 2].

Results of the present investigation may explain some of the reported variability in percent hindlimb shunt and earlier controversy regarding the normal baseline percent shunt in canine hindlimbs when pentobarbital was the anesthetic utilized, since times of anesthetic administration and shunt measurement were probably not controlled $[3,4,10,12]$. It has been previously suggested this variability may have been due to the lack of control of arterial blood gases [3, 4]. Experiments from our laboratories have suggested that this is not true [13].

It is apparent that intravenous pentobarbital alters both systemic and hindlimb hemodynamics when administered as a supplemental dose in the previously anesthetized dog. All hindlimb hemodynamic parameters (CFAQ, CFAR, AVA\%, AVAQ, and NCQ) in this study returned to the level of controls by 40 min when the drug was administercd slowly. Alterations in systemic hemodynamics were somewhat less abrupt and less sustained with the slower administration compared to the bolus administration of supplemental pentobarbital ancsthcsia. Using pentobarbital anesthesia in studies of extremity shunting utilizing radioactive microspheres is acceptable if the vasoactive effects of the drug are 
considered. The effects of other anesthetic agents on arteriovenous shunting are unknown. One may conclude from our data that experimental measurements in arteriovenous shunt studies as well as in metabolic studies investigating arteriovenous substrate differences should not begin, and baseline values should not be obtained, until 30 to $40 \mathrm{~min}$ following initial or supplemental administration of pentobarbital, if interpretive errors are to be avoided.

\section{REFERENCES}

1. Altura, B. T. and Altura, B. M. Pentobarbital and contraction of vascular smooth muscle. Amer. J. Physiol. 229: $1635,1975$.

2. Altura, B. T., Turlapaty, P., and Altura, B. M. Pentobarbital sodium inhibits calcium uptake in vascular smooth muscle. Biochim. Biophys. Acta 595: 309, 1980.

3. Delaney, J. P. and Scarpino, J. Limb arteriovenous shunting following sympathetic denervation. Surgery 73: 202, 1973.

4. Delaney, J. P., and Scarpino, J. Letters to the editor. Surgery 75: 154, 1974.

5. Fan, F. C., Schuessler, G. B., Chen, R. Y. Z., and Chien, $S$. Determinations of blood flow and shunting of 9- and 15- $\mu \mathrm{m}$ spheres in regional beds. Amer. $J$. Physiol. 237: H25, 1979.

6. Forsyth, R. P., and Hoffbrand, B. I. Redistribution of cardiac output after sodium pentobarbital anesthesia in the monkey. Amer. J. Physiol. 218: 214, 1970.

7. Harris, P. D., Hodoval, L. F., and Longnecker, D. E. Quantitative analysis of microvascular diameters during pentobarbital and thiopental anesthesia in the bat. Anethesiology 35: 337, 1971.

8. Kaihara, S., Van Heerden, P. D., Migita, T., and Wagner H. N., Jr. Measurement of distribution of cardiac output. J. Appl. Physiol. 25: 696, 1968.

9. Kazmers, A., Whitehouse, W. M., Jr., Lindenauer, S. M., and Stanley, J. C. Dissociation of glucagon's central and peripheral hemodynamic effects. Mechanisms of reduction and redistribution of canine hindlimb blood flow. J. Surg. Res. 30: 384, 1981.

10. Lopez-Majano, V., Rhodes, B. A., and Wagner, H. N., Jr. Arteriovenous shunting in extremities. $J$. Appl. Physiol. 27: 782, 1969.

11. MacCannell, K. L. The effect of barbiturates on regional blood flow. Canad. Anaesth. Soc. J. 16: 1, 1969.

12. Rhodes, B. A., Lopez-Majano, V., and Wagner, H. N., Jr. Letters to the editor. Surgery 75: 154, 1974.

13. Walsh, D. B., Ladin, D. A., Vahlsing, H. L., Zelenock, G. B., Cronenwett, J. L., Stanley, J. C., and Lindenauer, S. M. Stability of arteriovenous anastomotic blood flow during altered acid-base balance and oxygenation. Surg. Forum 32: 19, 1981. 